\title{
FUNCTIONAL FOODS FOR PREVENTION AND TREATMENT OF CANCER
}

\author{
SIDDHITA TIWARY, MD SADIQUE HUSSAIN*
}

Department of School of Pharmaceutical Sciences, Lovely Professional University, Phagwara, Punjab, India. Email: sadiquehussain007@gmail.com

Received: 02 December 2020, Revised and Accepted: 31 December 2020

\section{ABSTRACT}

After cardiovascular diseases, in most developed nations cancer is the second leading cause of mortality. Additional to the rising tumor-related behaviors, especially smoking in developing nations, the global prevalence of cancer keeps climbing primarily cos of the aging and expansion of the global population. Lung carcinoma, liver carcinoma, intestinal carcinoma, colorectal carcinoma, breast carcinoma, stomach carcinoma, etc., are the largest global burden of cancer types. More than half of all cases of cancer and mortality are considered preventable globally. There are food components that, beyond basic nutrition, provide health benefits. These functional foods are known to do more than just provide nutrients because they help to sustain health and thereby decrease the risk of disease. In recent times, functional foods have acquired enormous importance for their anticipated visualized involvement in the treatment of various pathologies such as cancer. To see the impact of functional foods on wellbeing or cancer or associated states, there are very few researches performed worldwide. Several functional foods derived from diverse sources, such as plants, animals, and microbial sources, have noticeable anticancer effects. In this review, we show light on the different types of cancers and also highlighted different functional foods that can help in the prevention as well as treatment of different types of carcinoma.

Keywords: Tumor, Global burden, Food components, Functional foods, Anticancer.

(C) 2021 The Authors. Published by Innovare Academic Sciences Pvt Ltd. This is an open access article under the CC BY license (http://creativecommons.org/ licenses/by/4.0/) DOI: http://dx.doi.org/10.22159/ajpcr.2021v14i3.40426. Journal homepage: https://innovareacademics.in/journals/index.php/ajpcr

\section{INTRODUCTION}

Globally, more than 18 million new cancer cases are reported each year [1]. Globally, cancer brings growing health and economic burden and has the greatest effect on the most vulnerable communities [2]. To identify possible risk factors and generate strategies for cancer prevention, understanding the current cancer burden in different regions is important [3]. Cancer is a disorder that involves irregular cell growth that is likely to invade the other areas of the organisms' body, maybe malignant (may easily spread), or benign tumors (cannot spread to other parts) that display signs such as a lump or atypical bleeding [4]. In both men and women in the USA, lung cancer is the most frequent cause of death [5]. In India, mortality due to cancer from 1990 to 2016 has doubled. India's prevalence of cancer is analyzed to be around 1.15 million new patients in 2018 and is expected to nearly double by 2040 as a result of the rise in population only [6]. The best way to minimize the burden of cancers remains primary prevention through lifestyle and environmental measures [7].

Functional foods also known as nutraceuticals are highly nutritious and have several health benefits like protection against disease providing any sort of nutrition deficit and providing health growth to individuals [8]. They differ from conventional food as their specific components have direct linking toward the wellbeing of the consumer and have appropriate physiological effects over health that is related to a single product whereas conventional food like low-fat products, vegetables provide a healthy diet to an individual as a whole food rather than having part of any of the single product [9]. Prebiotic (a non-digestive food ingredient) distresses the host by exciting the evolution and motion of specific bacteria in the colon and probiotic (the microbial dietary supplement) shows beneficial outcomes on health are often used as a functional food [10]. As a change in the era and so with the categories of functional food, the American egg (natural functional food) is an exceptional dietary source of many vital (protein, choline) and non-vital (lutein/zeaxanthin) components which may encourage ideal health [11]. Some major nutraceuticals that are used as functional food are fatty acid ( $\omega-3$ fatty acids, conjugated linolenic acid, butyric acid), carotenoids, and antioxidants are beneficial in the treatment of coronary heart disease, immune response disorder, cancer, stroke prevention, cancer, and cataracts [12]. Functional foods aid the consumer in prime an improved life without altering eating customs [13]. These days' functional foods are marketed as a new category of food products, having the availability of such benefits is due to the presence of their functional or active constituents [1]. Functional food was first labeled in Japan in the late $19^{\text {th }}$ century (the 1980s) for the food products that contain some detailed constituents that are therapeutically active and have some biological properties [14]. In china using of functional food means any illustration that privileges that the food product has certain physiological or nutritional quality, it can be any healthy function or activity that food will have a confident influence on the health and can be termed as a functional food [15]. Several studies have been done to aim the methodical sustaining of the calculated decision concerning functional food growth and these are firstly what is the health benefit these functional food claims; secondly which of the product they use and third about the communication format [16]. Certain plant-based functional food contains bioactive compounds and their pharmacological mechanism includes its hypolipidemic effect, these can be divided into six categories flavonoid, steroidal saponins, polysaccharides, alkaloids, and polyphenols. One of the mechanisms of action for the same is the inhibition of endogenous lipid biosynthesis [17]. A new category of functional food in the market can be listed as vitamins, minerals, antioxidants, omega- 3 fatty acid prebiotics, and probiotics but the problem of degradation is that the main issue with many of these bioactive compounds and solution for the same is the isolation of these compounds from the environment that favor degradation or any other unwanted interaction. The demand for functional food by a consumer is constantly increasing [18]. This review focuses on the functional foods that help in the remedy and management of neoplasm and different diseases like CV that is a major burden for all of nation across the globe.

\section{TYPES OF CANCER}

\section{Breast cancer}

Breast cancer remains the predominant cancer risk for women, with mortality of 53,5341 and disability-adjusted life years of 
14.8 million. In 2016, nearly 1.7 million cases of breast cancer emerged, making it globally the major cause of death and morbidity among females [19]. Every year, over a million people are expected to be diagnosed with breast tumors globally and over 410,000 will die of the illness, accounting for $14 \%$ of women [20]. There has been an overall rise in breast cancer diagnoses in recent years, due to many contributing factors. In 2017, an analysis showed a 33\% rise in cases from 2005 to 2015, while population growth was $12.6 \%$, aging $16.4 \%$, and age-specific cases $4.1 \%$ [21]. Reproductive risk factors include the long history of menstruation, nulliparity, the present utilization of the postmenopausal hormone treatment, or contraceptives. The use of alcohol can also increase breast cancer risk [22].

Male breast tumors may be linked to $<0.2 \%$ of deaths associated with cancer in men. Male breast tumor exists at a relatively low frequency, so study, clinical testing, and advancement of alternative drug methods are mainly focused on female cancer of the breast [23]. The low occurrence hypothesis between males is based on variations in hormones and a comparatively poor proportion of men's breast tissue. The malignancy is expected to be caused by an irregular absorption and metabolism of estrogen [24]. In contrast to female breast cancer, male breast carcinoma is infrequent and uncommon. Clearing this difference may be supported by a direct correlation with female breast cancer. Data in the Survival, Epidemiology, and End Results (SEER) program from 1973 to 2005 show that progress in the longevity of breast tumors in men has slipped behind that in women [25]. The best effective ways to reduce the chances of breast cancer are to maintain a healthy body, increase physical exercise, and limit the consumption of alcohol [26].

\section{Colorectal cancer}

Colorectal cancer is fourth among males and the third among females in terms of prevalence [27]. Colorectal cancer is primarily an elderly condition, with over $70 \%$ of people 65 years of age or older, and is a significant cause of illness and death in the aged. It is predicted that the number of cases will rise as age increases. It is the second most prevalent cancer in the United Kingdom [28]. Australia, Canada, New Zealand, the US, and regions of Europe are among the nations that have the highest occurrence rates. India, China, and portions of Africa are among the lowest-risk countries [29]. A substantial rise of 2-4 times in the occurrence of a colorectal tumor has occurred in Asian countries such as China, Japan, South Korea, and Singapore over the previous decades [30]. Every year around the world 1.8 million new cases are diagnosed [31]. Age, obesity, low intake of fruit and vegetables, lack of activity, smoking, excessive drinking of alcohol, and heavy consumption of refined or red meat are among the risk factors for colorectal cancer. However, developing countries around the world with a low risk of colorectal cancer have been developed, in recent years [32,33]. Fecal occult blood testing, digital rectal testing, and sigmoidoscopy are three available methods for screening of colorectal cancer. Sigmoidoscopy of these approaches has shown the biggest promise to minimize colorectal cancer mortality. The benefits of this screening procedure are that tumors in the rectum and distal colon can be diagnosed early and adenomatous polyps can be diagnosed and eliminated [34]. Despite advances in the management of this illness, 5 -year longevity is just 62\% in the US. Studies have shown that early diagnoses boost longevity and thus offer a basis for screening [35].

\section{Lung cancer}

About 100 types of cancer are categorized by organ and root tissue. Lung cancer is the primary cause of death of all these types. Every year, approximately 1.04 million new lung cancer cases are recorded globally, with the highest occurrence in North America and Europe [36]. In some nations, this epidemic of lung cancer mortality has decreased where tobacco control results in smoking but in other countries, it is rising rapidly [37]. Despite years of study, the outlook for lung cancer patients remains dysfunctional, with a survival rate of $14 \%$ across 5 years. However, in the early stages, lung cancer is treatable and most patients benefit from therapy, for example, prolonged lifespan or reduced symptoms [38]. The chance of getting lung cancer is $20-30$ times higher than that of a non-smoker in his or her lifetime [39]. In developing nations, rates of lung cancer are increasing parallel to cigarette smoking. Future prevention and studies may concentrate on modifiable non-tobacco risk factors and explain the state-of-the-art exposures including non-cigarette products [40]. The 2004-2008 SEER data revealed the medium age of 71 years when lung cancer has been diagnosed. In patients under 20 years, no cases were diagnosed [41].

\section{Stomach cancer}

Stomach cancer (gastric carcinoma) is now the solitary most frequent and fatal malignancy in the globe, although it continuously declines in occurrence. Gastric cancer is the third largest cause of tumor mortality around the world, according to GLOBOCAN 2018 information. Stomach cancer, after cancers of the lungs, breasts, colorectal, and prostate is the fifth most frequently diagnosed neoplasm across the globe [42,43]. The primary causes of stomach cancer are unclear but diet plays a significant part in the advancement of this condition has been presumed. The nitrate or nitrate-rich foods and their products are widely implicated as causative agents. Studies have also indicated an elevated risk of gastric cancer from a diet high in carbohydrates or a high-salt diet [44]. The risk factors for stomach cancer also include smoking and Helicobacter pylori infection [45]. The stomach is the first location where food enters in sustained contact with gastrointestinal mucosa and several carcinogens and carcinogenic antagonists are found in the human food. It is fair to conclude from these results that environmental factors, in particular dietary factors, have the key etiological effects for stomach cancer [46].

Green and yellow vegetables contain high levels of Vitamin C and have been reported in many laboratory and epidemiological trials as defensive against stomach cancer. Research indicates that a highVitamin C diet can help, whereas a high-salt diet can increase the risk of stomach cancer [47]. In East Asia, Latin America, and Eastern Europe, and within particular subgroups in the USA, gastric cancer occurrence and mortality remain vastly disproportionate. Many reductions in gastric cancer resulted incidentally, due to better sanitation, hygiene, safe water supply, and improvements in food safety, quality, and availability [48].

\section{Liver cancer}

Liver cancer is the sixth-largest tumor diagnosed and the second largest cause of mortality around the globe. Around half the new cases and deaths were in China alone, with 466,100 cases and 422,100 deaths in 2015 [49]. In most countries, hepatocellular carcinoma (HCC) is the main histologic form of liver cancer and accounts for about $80 \%$ of total cases. The $2^{\text {nd }}$ most frequent histologic form is intrahepatic cholangiocarcinoma, which accounts for around $15 \%$ of total cases [50]. There will be 1 million cases by 2030, and the burden of liver cancer is rising worldwide. Due to the highest prevalence of hepatitis B virus (HBV) infections in Sub-Saharan Africa and Asia, the morbidity of liver cancer is also high [51]. The major causing factor for the HCC histological form of liver cancer is HBV and/or HCV infections [52]. These causes have been identified as possible causing factors of liver carcinoma, such as dietary aflatoxin, betel nut chewing, alcohol intake, and smoking [53,54]. Since major risk factors of liver cancer can be changed, there are good hopes that prevention interventions such as improvements to the diet and hepatitis immunization can decrease the occurrence and death from the disease. Some of its etiological factors such as hepatitis infection and cirrhosis can be easily identified through screening to decrease liver cancer growth [55].

\section{Pancreatic cancer}

Pancreatic cancer, with which death is nearly parallel, is an extremely lethal disease. More than 2,00,000 deaths annually occur from pancreatic cancer globally [56]. Pancreatic cancer is less frequent from a global perspective than the lung, breast, stomach, liver, large bowel, and prostate tumors [57]. The $4^{\text {th }}$ common cause of carcinogenic mortality in developing countries is pancreatic cancer but forecasted to be the $2^{\text {nd }}$ leading cause for cancer-related death in the next 10 years if the figures are not changed [58]. Adenocarcinoma (accounts for nearly 
$85 \%$ of all cases) and pancreas endocrine tumors (represent fewer than $5 \%$ of all cases) are two primary forms of tumors in pancreatic cancer [59]. Smoking, chronic pancreatitis family history, aging, male, diabetic mellitus, obesity, non-O blood type, occupational exposures, African-American ethnicities, heavy fat diet, meat-rich diet, poor vegetable, and folate-related diets, and potential $H$. pylori are the main factors for this malignant condition. Although the cause of pancreatic cancer is complicated, multifactorial, cigarette smoking, and family history are prevalent [60]. Smoking rates raises the likelihood of pancreatic cancer, and it is suspected that smoking may be linked to as much as one in four cases of pancreatic cancer [61]. Present screening practices are restricted to individuals with family history and those considered to raise the risk of catching the disorder, often done with MRI or endoscopic ultrasound [62].

\section{LIST OF ANTICANCER FUNCTIONAL FOODS}

Europe scientific institute defined functional food as "a food product can only be considered as functional, if together with the basic nutritional impact it has a beneficial effect on one or more function of the human organism thus either by improving general and physical health or decreasing the risk of evolution of disease" [14]. Functional food often-called nutrition providing substances shows potentially active behavior in the treatment and prevention of cancer. Whey protein shows up ground-breaking and the suppositions have been made with confirmations that it segregates has a cytotoxic impact on melanoma. A lesser number of tumor foci was seen when whey protein hydrolysate was taken care of by two colon malignant growth bearing rodents [63]. Table 1 represents the list of functional foods along with their biological applications.

Cruciferous vegetables such as broccoli, cauliflower, and cabbage contain certain non-nutritional phytochemicals that are beneficial for cancer prevention, whereas onion and garlic contain certain biologically active compounds that have anticarcinogenic and anticholinergic effects, other functional foods include functional milk, dairy products, sea buckthorns, and some functional seafood lipid and proteins [65]. Whey protein or milk protein shows anticancer activity, as a functional food helps in the handling of chronic disease $[66,67]$. Folate a water solvable fully oxidized form of Vitamin B, it plays a significant share in the expansion of certain disease like cancer [68]. Linola seed holds oil that is amusing in linoleic acid and yield conjugated linoleic acid beneficially diminishes the jeopardy of breast cancer in women [69]. Functional food is used as CMDs medications because of its latent properties such as anti-inflammatory, antioxidants, antiestrogenic, and immunomodulatory; other purified bioactive complexes are superior to pharmaceutical drugs for the dealing of unembellished chronic symptoms [70]. Phenolic and polyphenolic compounds act as a specific part of secondary metabolites of plants that turn as free radical scavengers and inhibitors of LDL fatty acid oxidation and DNA cracking. As a result, dietary polyphenols are used to prevent cardiovascular diseases (CVDs) and certain tumors [71]. Prunes (Prunus domestica L.), dried plums fruits are very rich in bioactive compounds, their phenolic compounds inhibit human LDL oxidation in vitro, and plays a protective role against chronic disease cancer [72].

Table 1: List of functional foods with their biological applications [64]

\begin{tabular}{lll}
\hline S. No. & Functional foods & Biological application \\
\hline 1 & $\begin{array}{l}\text { Tea, onion, mushroom, } \\
\text { ginger, garlic, carrot, } \\
\text { berry }\end{array}$ & Decrease lipid, Anticarcinogenic \\
2 & $\begin{array}{l}\text { Apple, beetroot, } \\
\text { broccoli, ginger, spinach }\end{array}$ & $\begin{array}{l}\text { Enhanced drug detoxification, } \\
\text { Anticarcinogenic }\end{array}$ \\
3 & $\begin{array}{l}\text { Garlic, green tea, onion } \\
\text { Cabbage, fennel, }\end{array}$ & $\begin{array}{l}\text { Antibacterial, Anticarcinogenic } \\
\text { Antiestrogenic, Anticarcinogenic }\end{array}$ \\
5 & $\begin{array}{l}\text { soybean } \\
\text { Garlic, green tea, orange }\end{array}$ & Anticarcinogenic \\
\hline
\end{tabular}

Apple

Apples are a major wellspring of dietary phytoconstituents like flavonoids. They additionally contain significant levels of polyphenols also, and different phytochemicals. The utilization of one apple daily was accounted for to lessen the danger of colorectal malignancy. The study also prophesied that the danger of colorectal tumor condensed around 50\% upon feeding of supplementary per day an apple [73]. Apple phloretin $(\mathrm{Ph})$, which can be acquired from apples and juices, is a popular inhibitor of the sort II glucose carrier (GLUT2). Expanded articulation of GLUT2 has been found in numerous human neoplasm tissues, including liver, breast, and gastric malignancy cells [74]. Apple extricates essentially restrained the TNF-R-initiated $\mathrm{NF}^{-} \mathrm{B}$ enactment at a portion of $5 \mathrm{mg} / \mathrm{ml}$. In malignant growth cells, $\mathrm{NF}_{\mathrm{K}} \mathrm{B}$ instigates protection from anticancer chemotherapeutic operators by expanding cell expansion and restraining apoptosis. Along these lines, restraint of $\mathrm{NF}_{\mathrm{K}} \mathrm{B}$ actuation in malignant growth cells is profitable in disease treatment by lowing the obstruction to chemotherapy [75]. Subsequently, apple utilization has been connected to a brought down danger of malignant growth [76].

\section{Beetroot}

Beetroot (Beta vulgaris L.) is a normally expended vegetable, which moreover has solid antioxidant properties. Beetroots and their juices from biological invention have a high content of bioactive complexes [77]. These nontoxic plants, when utilized and mixed with intense anti-cancer medications, for example, doxorubicin (Adriamycin), can act synergistically and relieve treatment-related medication poisonousness. Betanin, the betacyanin constituent essentially answerable for red beet shading, is a cancer prevention agent with an especially highly free radical-searching action and is a modulator of oxidative pressure [78]. Red beetroot leave is a common Mediterranean diet vegetable, which is an abundant and inexpensive source of natural antioxidant and anticancer nutrients and can be added to juice as it improves the juice's nutritional value and does not have a significant effect on its sensory properties [79].

\section{Blueberry}

Anthocyanins are reddish natural pigments, a category of flavonoids, widely circulated in fruit and particularly in blueberries (Vaccinium spp.). Epidemiological studies have associated their intake favorably with decreased mortality due to CVDs and some cancer types [80]. One of the natural and edible items containing a rich source of phenolic dietary compounds is Blueberry. Quercetin was previously shown to have cytotoxic effects on cancer in vitro as one of the most abundant dietary phenolic compounds present in blueberry extracts. Kaempferol is a blueberry extract flavonol similar to quercetin that has previously been shown to be effective for its anticarcinogenic effects [81]. In vivo and in vitro analysis of berries as antioxidants and anti-cancer agents has enhanced our understanding of the complex mechanism and their impact on population health and illnesses [82]. Blueberries act through pathways by which carcinogenesis has been prevented by inhibiting the production of pro-inflammatory molecules and oxidizing stress and products, such as DNA damage, inhibiting cell growth, and increased apoptosis [83].

\section{Ginger}

Ginger (Zingiber officinale) is an internationally recognized plant used in cooking and has long been considered to have therapeutic properties [84]. Ginger (Z. officinale), an individual from the Zingiberaceae family, contains sugars (50-70\%), lipids (3-8\%), terpenes, and phenol mixes as a constituent of ginger rhizome. Other than these, amino acids, crude fiber, debris, protein, phytosterols, nutrients, and minerals are additionally present [85]. The ginger has a huge part in treating a few infections including gastrointestinal complexities, treat stomach upset, looseness of the bowels, rheumatic problems, queasiness, basic colds, fever, and tipsiness. Furthermore, ginger has antineoplastic and chemopreventive properties. Ginger root and its fundamental phenolic mixes, for example, gingerols and zerumbone have anticarcinogenic action, cancer prevention agents, and calming movement by prompting 
apoptosis in malignant growth cells [86]. The Zingiberaceae plants contain fundamental oils which include terpenoids, phenylpropanoids, flavonoids, and sesquiterpenes that have noteworthy antitumor action [87]. Steamed ginger provides a new source of chemical variation in its structure as compared to unprocessed ginger. Recently, a study found that ginger steam treatment substantially improved its anticarcinogenic effects on colon cancer [88].

\section{Grapes}

Grapes are rich in polyphenols that are beneficial for the treatment of breast cancer it shows pro-apoptotic, anti-proliferative, anti-invasive, anti-angiogenic, and anti-metastatic action in breast cancer [89]. Resveratrol a polyphenolic compound in grapes is one of the potent anticancer agents; these compounds show the progression-inhibition effect on cancer cells [90]. Resveratrol derivatives slow the growth of cancer cells and manage $\mathrm{CV}$ effects also a neuroprotective and prevent metabolic diseases. Pterostilbene and piceid show a similar effect and inhibit cell proliferation as resveratrol on cellular antioxidation systems by enhancing cellular resistance [91]. Resveratrol additionally incorporates a few stages to detoxification or cell reinforcement compounds by actuating a redox touchy record factor [92]. Apoptosis is induced by resveratrol with the initiation of P53 and by suppression of protein translation in T47D human breast cancer [93].

\section{Mushroom}

Mushroom (Inonotus obliquus) has been utilized as a useful food and conventional Chinese spices for a long time, having anti-inflammatory, calming, and anticancer constituents [94]. Homopolysaccharides are accepted to be the key active mushrooms' polysaccharides, different sorts of polysaccharides of mushroom have natural properties such as anti-obesity, antidiabetic, antiviral, antimicrobial, and anticarcinogenic impacts that exhibit the numerous wellbeing advancing potential [95]. Therapeutic mushrooms with anticancer activity involve polysaccharides, polysaccharide-protein edifices, dietary fibers, specific sorts of proteins, terpenoids, steroids, phenols, and so forth [96]. In Traditional Chinese Medicine, Cordyceps has been utilized to treat a few conditions including cancer [97].

\section{Onions}

Onion is one of the most broadly and to a great extent devoured vegetables. From epidemiologic considers, onion utilization is popularly connected to decreased paces of cardiac illness [98]. Onions are crammed with hostile to malignancy sulfur mixes which are profoundly gainful for disease chemoprevention. Progressed contemplates having indicated that onion might be hinder the liver, colon, prostate, cellular breakdown in the lungs, and so forth with high cancer prevention properties [99]. Allium utilization has been contrarily recommending a chemoprotective function, for example, onions [100]. Fig. 1 shows different functional foods along with where they act in different stages of tumor progression.

Various natural carotenoids (natural fat-soluble pigment) such as carotene, lutein, zeaxanthin, lycopene, and astaxanthin besides beta carotene were proven to have anticholinergic activities; they inhibit cancer cell proliferation [101]. Moringa otherwise called horseradish tree or drumstick tree is the most read species for its anticancer activity and are utilized in nations where malnutrition is a colossal issue because its flowers, cases, leaves, and seeds contain great dietary benefit and used to forestall lack of healthy sustenance in individuals, and because of the nearness of certain bioactive compounds which shows pharmacological properties that show anticancer exercises and is possibly utilized as a functional food [102]. Tea polyphenol shows preventive measures against osteoporosis, cancer, and CVDs for those who consume three cups of tea per day [103]. Artichoke can be used as a source of functional food that prevents cancer in individuals [104]. Furthermore, these Palaeolithic eating regimens such as lean meats, fish, organic products, vegetables, nuts, and seeds show promising outcome in the counteraction of malignant growth cancer and all other CVDs as they contain $\omega-3$ unsaturated fat, polyphenols, filaments, and plan sterols these bioactive mixes lessen the occurrence of illness like cancer [70]. Rice bran is an ironic basis of dietary fiber, minerals, vitamins, and vital fatty acids. Various revisions specify that rice is high in $\gamma$-oryzanol, which hinders tumor advancement [105]. The use of flaxseed has beneficial effects on colon physiology with a reduction in risk of or occurrences of colorectal cancer in both human and animal experiments. Taken separately, the risk from colonic neoplasms decreased, and cell growth management by several possible pathways is also correlated with each of its principal bioactive components including fibers, alpha-linolenic acid, lignans, and other phytochemicals [106]. Banana peel extract is listed as non-toxic to normal cells in compliance with the standards defined by the National Cancer Standard Institute [107].

Chronic non-transmittable diseases such as metabolic disorder, Type2 diabetes, CVDs, and cancer happen because of helpless dietary propensities and upset way of life that can be treated by moving to a more advantageous eating regimen and refreshments decision [108]. The advancement of human eating routine since the past numerous years from the Palaeolithic eating regimen to the modern form of

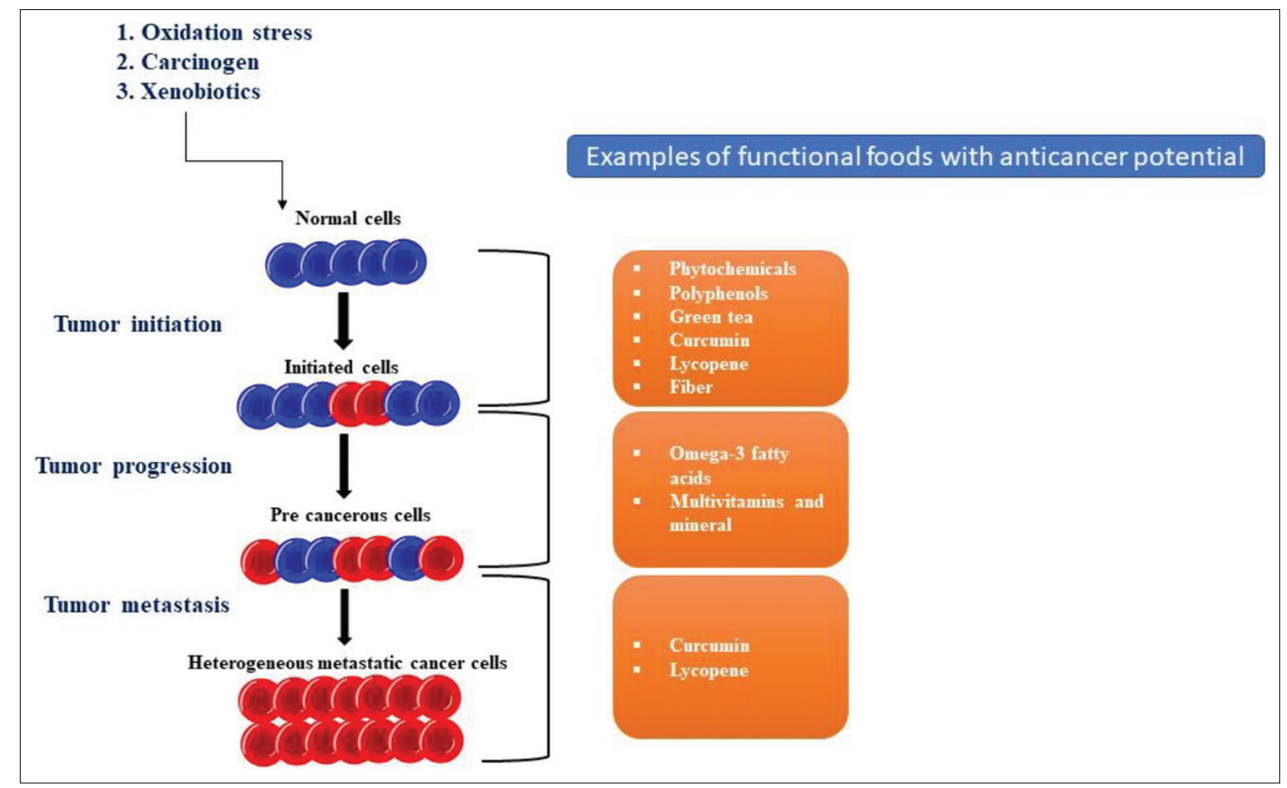

Fig. 1: The stages of tumor progression and where different functional food acts for the management 
food has changed a ton that brings about stoutness and interminable illness such as CVDs and diabetes [109]. Functional foods built on their rudimentary nourishing roles can cut the hazard of many chronic diseases and show functional benefits, promoted with the privilege of their capability to diminish cardiac conditions, focusing mainly on recognized risk aspects, such as hyperlipidemia, diabetes, obesity, and raised lipoprotein [110]. Strategies have been made for the prevention of malignancy in humans with amplified ingesting of functional foods such as barley, brown rice, buckwheat, and whole grains and vegetables such as broccoli, cabbage, garlic, mushrooms, and onions, or some drinks such as coffee and green tea [111].

\section{CONCLUSION}

A balanced, well-working body culminates in an adequate diet, resulting in the achievement of proper human physiology, thus balanced living. Dietary variables are recognized as having a major impact on cancer risk, with risks being both increased and decreased by various dietary components. Diets are associated with many deaths from cancer, while physical inactivity tends to be associated with the risk of cancer. Researchers have made progress in our understanding of the relationship between functional foods and cancers in recent decades, especially in the area of prevention. In general, this paper addresses functional foods for cancer prevention and health benefits. Some functional foods such as green tea and red grapes have demonstrated anticancer efficacy by inhibiting pathological angiogenesis. Through the scavenging of free radicals, some functional foods displayed anticancer activity, such as berries, broccoli, cabbage, carrots, cauliflower, chocolate, garlic, grapes, green tea, onions, soybeans, tomatoes, prunes, and citrus fruits. The intrinsically chemopreventive existence of foods and/or their components and functional foods should not be completely believed and acknowledged.

\section{AUTHORS' CONTRIBUTIONS}

Both the authors have contributed equally.

\section{CONFLICTS OF INTEREST}

The author(s) declared no potential conflicts of interest concerning the research, authorship, and/or publication of this article.

\section{AUTHORS' FUNDING}

The author(s) received no financial support for the research, authorship, and/or publication of this article.

\section{REFERENCES}

1. Richters A, Aben KK, Kiemeney LA. The global burden of urinary bladder cancer: An update. World J Urol 2019;38:1895-904.

2. Wild CP. The global cancer burden: Necessity is the mother of prevention. Nat Rev Cancer 2019;19:123-4.

3. Cai Z, Liu Q. Understanding the global cancer statistics 2018: Implications for cancer control. Sci China Life Sci 2019;62:9816.

4. Ames BN, Gold LS, Willett WC. The causes and prevention of cancer. Proc Natl Acad Sci 1995;92:5258-65.

5. Alberg AJ, Samet JM. Epidemiology of lung cancer. Chest 2003;123:21-49.

6. Smith RD, Mallath MK. History of the growing burden of cancer in India: From antiquity to the $21^{\text {st }}$ century. J Global Oncol 2019;5:1-15.

7. Danaei G, Hoorn VS, Lopez AD, Murray CJ, Ezzati M. Causes of cancer in the world: Comparative risk assessment of nine behavioural and environmental risk factors. Lancet 2005;366:1784-93.

8. Urala N, Lahteenmaki L. Consumers changing attitudes towards functional foods. Food Qual Prefer 2007;18:1-12.

9. Urala N, Lahteenmaki L. Attitudes behind consumers willingness to use functional foods. Food Qual Prefer 2004;15:793-803.

10. Roberfroid BM. Prebiotics and probiotics: Are they functional foods. Am J Clin Nutr 2000;71:1682S-7S; discussion 1688S-90S.

11. Hasler CM. The changing face of functional foods. J Am Coll Nutr 2000;19 Suppl 5:499-506.

12. McClements DJ, Decker EA, Park Y, Weiss J. Structural design principles for delivery of bioactive components in nutraceuticals and functional foods. Crit Rev Food Sci Nutr 2009;49:577-606.

13. Bech-Larsen T, Grunert KG. The Perceived healthiness of functional food a conjoint study of Danish, Finnish, and American consumers perceptions on functional food. Appetite 2003;40:9-14

14. Siro I, Kápolna E, Kápolna B, Lugasi A. Functional food. Product development, marketing and consumer acceptance a review. Appetite 2008;51:456-67.

15. Yang Y. Scientific substantiation of functional food health claims in China. J Nutr 2008;138:1199-205.

16. Kleef VE, Trijp HC, Luning P. Functional foods: health claim-food product compatibility and the impact of health claim framing on consumer evaluation. Appetite 2005;44:299-308.

17. Gong X, Li X, Xia Y, Xu J, Li Q, Zhang C, et al. Effects of phytochemicals from plant-based functional foods on hyperlipidemia and their underpinning mechanisms. Trends Food Sci Technol 2020;103:304-20.

18. Smith J, Charter E. Functional Food Product Development. Hoboken, New Jersey: Wiley-Blackwell; 2010.

19. Sharma R. Breast cancer incidence, mortality and mortality-toincidence ratio (MIR) are associated with human development, 19902016: Evidence from global burden of disease study 2016. Breast Cancer 2019;26:428-45.

20. Coughlin SS, Ekwueme DU. Breast cancer as a global health concern. Cancer Epidemiol 2009;33:315-8.

21. Azamjah N, Soltan-Zadeh Y, Zayeri F. Global trend of breast cancer mortality rate: A 25-year study. Asian Pac J Cancer Prev 2019;20:2015-20.

22. Jemal A, Bray F, Center MM, Ferlay J, Ward E, Forman D. Global cancer statistics. CA Cancer J Clin 2011;61:69-90.

23. Gucalp A, Traina TA, Eisner JR, Parker JS, Selitsky SR, Park BH, et al. Male breast cancer: A disease distinct from female breast cancer. Breast Cancer Res Treat 2019;173:37-48.

24. Hussain MS, Mohapatra C. Male breast cancer: Signs, symptoms, and treatment: A review. Int J Creat Res Thoughts 2020;8:553-61.

25. Liu N, Johnson KJ, Ma CX. Male breast cancer: An updated SEER data analysis. Clin Breast Cancer 2018;18:997-1002.

26. Kushi LH, Doyle C, McCullough M, Rock CL, Demark-Wahnefried W, Bandera EV, et al. American cancer society guidelines on nutrition and physical activity for cancer prevention reducing the risk of cancer with healthy food choices and physical activity. CA Cancer J Clin 2012;62:30-67.

27. Parkin M, Bray F, Ferlay J, Pisani P. Global cancer statistics, 2002. CA Cancer J Clin 2005;55:74-108.

28. Simmonds PD, Best L, George S, Baughan C, Buchanan R, Davis C, et al. Surgery for colorectal cancer in elderly patients: A systematic review. Lancet 2000;356:968-74.

29. Haggar FA, Boushey RP. Colorectal cancer epidemiology: Incidence, mortality, survival, and risk factors. Clin Colon Rectal Surg 2009;22:191-7.

30. Sung JJ, Lau JY, Goh KL, Leung WK. Increasing incidence of colorectal cancer in Asia: Implications for screening. Lancet Oncol 2005;6:871-76.

31. Keum N, Giovannucci E. Global burden of colorectal cancer: Emerging trends, risk factors and prevention strategies. Nat Rev Gastroenterol Hepatol 2019;16:13-32.

32. Center MM, Jemal A, Smith RA, Ward E. Worldwide variations in colorectal cancer. CA Cancer J Clin 2009;59:366-78.

33. Center MM, Jemal A, Smith RA, Ward E. International trends in colorectal cancer incidence rates. Cancer Epidemiol Biomarkers Prev 2009; 18:1688-94.

34. Newcomb PA, Norfleet RG, Storer BE, Surawicz TS, Marcus PM. Screening sigmoidoscopy and colorectal cancer mortality. J Natl Cancer Inst 1992;84:1572-5.

35. Hawk ET, Levin B. Colorectal cancer prevention. J Clin Oncol 2005;23:378-91.

36. Sharma P, Mehta M, Dhanjal DS, Kaur S, Gupta G, Singh H, et al. Emerging trends in the novel drug delivery approaches for the treatment of lung cancer. Chem Biol Interact 2019;309:108720.

37. Wender R, Fontham ET, Barrera E, Colditz GA, Church TR, Ettinger DS, et al. American cancer society lung cancer screening guidelines. CA Cancer J Clin 2013;63:106-17.

38. Spira A, Ettinger DS. Multidisciplinary management of lung cancer. N Engl J Med 2004:350:379-92.

39. Minna JD, Roth JA, Gazdar AF. Focus on lung cancer. Cancer Cell 2002;1:49-52

40. Bade BC, Cruz CS. Lung cancer 2020 epidemiology, etiology, and prevention. Clin Chest Med 2020;41:1-24.

41. Cruz CS, Tanoue LT, Matthay RA. Lung Cancer: Epidemiology, 
etiology, and prevention. Clin Chest Med 2011;32:605-44.

42. Rawla P, Barsouk A. Epidemiology of gastric cancer: Global trends, risk factors and prevention. Gastroenterol Rev 2019;14:26-38.

43. Yang L, Zheng R, Wang N, Yuan Y, Liu S, Li H, et al. Incidence and mortality of stomach cancer in China, 2014. Chin J Cancer Res 2018;30:291-8.

44. Nomura A, Grove JS, Stemmermann GN, Severson RK. A prospective study of stomach cancer and its relation to diet, cigarettes, and alcohol consumption. Cancer Res 1990;50:627-31.

45. Kono $\mathrm{S}$, Hirohata T. Nutrition and stomach cancer. Cancer Causes and Control 1996;7:41-55.

46. Lee JK, Park BJ, Yoo KY, Ahn YK. Dietary factors and stomach cancer: A case-control study in Korea. Int J Epidemiol 1995;24:33-41.

47. Ngoan LT, Mizoue T, Fujino Y, Tokui N, Yoshimura T. Dietary factors and stomach cancer mortality. Br J Cancer 2002;87:37-42.

48. Balakrishnan M, George R, Sharma A, Graham DY. Changing trends in stomach cancer throughout the world. Curr Gastroenterol Rep $2017 ; 19: 36$

49. Fu J, Wang H. Precision diagnosis and treatment of liver cancer in China. Cancer Lett 2017;1-6.

50. Petrick JL, Braunlin M, Laversanne M, Valery PC, Bray F, McGlynn KA. International trends in liver cancer incidence, overall and by histologic subtype, 1978-2007. Int J Cancer 2016;139:1534-45.

51. Sia D, Villanueva A, Friedman SL, Llovet JM. Liver cancer cell of origin, molecular class, and effects on patient prognosis. Gastroenterol 2017:152:745-61.

52. Martel C, Maucort-Boulch D, Plummer M, Franceschi S. Worldwide relative contribution of hepatitis $\mathrm{B}$ and $\mathrm{C}$ viruses in hepatocellular carcinoma. Hepatol 2015;62:1190-200

53. Zheng R, Qu C, Zhang S, Zeng H, Sun K, Gu X. Liver cancer incidence and mortality in China: Temporal trends and projections to 2030. Chin J Cancer Res 2018;30:571-9.

54. Joshi S, Song YM, Kim TH, Cho SI. Socio-economic status and the risk of liver cancer mortality: A prospective study in Korean men. Public Health 2008;122:1144-51.

55. Wong MC, Jiang JY, Goggins WB, Liang M, Fang Y, Fung FD. International incidence and mortality trends of liver cancer: A global profile. Sci Rep 2017;7:45846.

56. Kamisawa T, Wood LD, Itoi T, Takaori K. Pancreatic cancer. Lancet 2016;388:73-85.

57. Lowenfels AB. Epidemiology and risk factors for pancreatic Cancer. Best Pract Res Clin Gastroenterol 2006;20:197-209.

58. Kleeff J, Korc M, Apte M, Vecchia CL, Johnson CD, Biankin AV. Pancreatic cancer. Nat Rev Dis 2016;2:16022.

59. Ilic M, Ilic I. Epidemiology of pancreatic cancer. World J Gastroenterol 2016;22:9694-705.

60. Vincent A, Herman J, Schulick R, Hruban RH, Goggins M. Pancreatic cancer. Lancet 2011;378:607-20.

61. Maitra A, Hruban RH. Pancreatic Cancer. Annu Rev Pathol 2008;3:157-88.

62. Siegel RL, Miller KD, Jemal A. Cancer statistics, 2020. CA Cancer J Clin 2020;70:7-30.

63. Hidron AI, Edwards JR, Patel J, Horan TC, Sievert DM, Pollock DA, et al. NHSN annual update: Antimicrobial-resistant pathogens associated with healthcare-associated infections: annual summary of data reported to the national healthcare safety network at the centers for disease control and prevention, 2006-2007. Infect Control Hosp Epidemiol 2008;29:996-1011.

64. Milner JA. Functional foods: the US perspective. Am J Clin Nutr 2000;71:1654-9.

65. Mazza G. Functional Foods: Biochemical and Processing Aspects. Boca Raton, Florida: CRC Press; 1998.

66. McIntosh GH, Royle PJ, Leu RK, Regester GO, Johnson MA, Grinsted RL, et al. Whey proteins as functional food ingredients. Int Dairy J 1998;8:425-34.

67. Parodi PW. A role for milk proteins and their peptides in cancer prevention. Curr Pharm Des 2007:13:813-28

68. Kim YI. Folate: A magic bullet or a double-edged sword for colorectal cancer prevention. Gut 2006;55:1387-9.

69. Oomah BD. Flaxseed as a functional food source. J Sci Food Agric 2001;81:889-94.

70. Lyu M, Wang YF, Fan GW, Wang XY, Xu SY, Zhu Y. Balancing herbal medicine and functional food for prevention and treatment of cardiometabolic diseases through modulating gut microbiota. Front Microbiol 2017;8 2146

71. Shahidi F. Functional foods: Their role in health promotion and disease prevention. J Food Sci 2004;69:146-9.

72. Stacewicz-Sapuntzakis M, Bowen PE, Hussain EA, Damayanti-
Wood BI, Farnsworth NR. Chemical composition and potential health effects of prunes: A functional food. Crit Rev Food Sci Nutr 2001;41:251-86.

73. Tu SH, Chen LC, Ho YS. An apple a day to prevent cancer formation: Reducing cancer risk with flavonoids. J Food Drug Anal 2017;25:119-24.

74. Yang KC, Tsai CY, Wang YJ, Wei PL, Lee CH, Chen JH, et al. Apple polyphenol phloretin potentiates the anticancer actions of paclitaxel through induction of apoptosis in human hep G2 cells. Mol Carcinog 2009;48:420-31.

75. Yoon H, Liu RH. Effect of selected phytochemicals and apple extracts on NF- $\mathrm{KB}$ activation in human breast cancer MCF-7 cells. J Agric Food Chem 2007;55:3167-73.

76. Yang J, Liu RH. Synergistic effect of apple extracts and quercetin $3-\beta$-D-glucoside combination on antiproliferative activity in MCF-7 human breast cancer cells in vitro. J Agric Food Chem 2009;57:8581-6.

77. Kazimierczak R, Hallmann E, Lipowski J, Drela N, Kowalik A, Püssa T, et al. Beetroot (Beta vulgaris L.) and naturally fermented beetroot juices from organic and conventional production: Metabolomics, antioxidant levels and anticancer activity. J Sci Food Agric 2014;94:2618-29.

78. Kapadia GJ, Rao GS. Anticancer effects of red beet pigments. In: Red Beet Biotechnology. Boston, MA; Springer; 2013.

79. Zein H, Hashish AE, Ismaiel G. The antioxidant and anticancer activities of Swiss chard and red beetroot leaves. Curr Sci Int 2015;4:491-8.

80. Faria A, Pestana D, Teixeira D, De Freitas V, Mateus N, Calhau C. Blueberry anthocyanins and pyruvic acid adducts: Anticancer properties in breast cancer cell lines. Phytotherapy Res 2010;24:1862-9.

81. Sezer ED, Oktay LM, Karadadas E, Memmedov H, Gunel NS, Sözmen E. Assessing anticancer potential of blueberry flavonoids, quercetin, kaempferol, and gentisic acid, through oxidative stress and apoptosis parameters on HCT-116 cells. J Med Food 2019;22:1118-26.

82. Baby B, Antony P, Vijayan R. Antioxidant and anticancer properties of berries. Crit Rev Food Sci Nutr 2018;58:2491-507.

83. A Johnson S, H Arjmandi B. Evidence for anti-cancer properties of blueberries: A mini-review. Anticancer Agents Med Chem 2013; 13:1142-8

84. Hung JY, Hsu YL, Li CT, Ko YC, Ni WC, Huang MS, et al. 6-Shogaol, an active constituent of dietary ginger, induces autophagy by inhibiting the AKT/mTOR pathway in human non-small cell lung cancer A549 cells. J Agric Food Chem 2009;57:9809-16.

85. Prasad S, Tyagi AK. Ginger and its constituents: Role in prevention and treatment of gastrointestinal cancer. Gastroenterol Res Pract 2015;2015:142979.

86. Ramakrishnan R. Anticancer properties of Zingiber officinale-Ginger: A review. Int J Med Pharm Sci 2013;3:11-20

87. Jeena K, Liju VB, Kuttan R. Antitumor and cytotoxic activity of ginger essential oil (Zingiber officinale Roscoe). Int J Pharm Pharm Sci 2015;7:341-4

88. Wang CZ, Qi LW, Yuan CS. Cancer chemoprevention effects of ginger and its active constituents: potential for new drug discovery. Am J Chin Med 2015;43:1351-63

89. Castillo-Pichardo L, Rivera-Rivera A, Dharmawardhane S. Potential of grape polyphenols as breast cancer therapeutics. OA Altern Med 2013;1:9.

90. Yoo KM, Kim S, Moon BK, Kim SS, Kim KT, Kim SY, et al. potential inhibitory effect of resveratrol derivative on progression of prostate cancer, Arch Pharm Chem Life Sci 2006;339:238-41

91. Stuart JA, Robb EL. Bioactive Polyphenols from Wine Grapes. New York: Springer; 2013.

92. Kundu JK, Surh YJ. Molecular mechanisms underlying chemoprevention with resveratrol. Cancer Prevent Res 2005;10:89-98.

93. Alkhalaf M. Resveratrol-induced apoptosis is associated with activation of p53 and inhibition of protein translation in T47D human breast cancer cells. Pharmacology 2007;80:134-43.

94. Ma L, Chen H, Dong P, Lu X. Anti-inflammatory and anticancer activities of extracts and compounds from the mushroom Inonotus obliquus. Food Chem 2013;139:503-8

95. Friedman M. Mushroom polysaccharides: chemistry and antiobesity, antidiabetes, anticancer, and antibiotic properties in cells, rodents, and humans. Foods 2016;5:80.

96. Ivanova TS, Krupodorova TA, Barshteyn VY, Artamonova AB, Shlyakhovenko VA. Anticancer substances of mushroom origin. Exp Oncol 2014;36:58-66.

97. Khan MA, Tania M, Zhang D, Chen H. Cordyceps mushroom: A potent anticancer nutraceutical. Open Nutraceutical J 2010;3:179-83.

98. Alpsoy S, Uygur R, Aktas C, Topcu B, Kanter M, Erboga M, et al. The effects of onion (Allium cepa) extract on doxorubicin-induced 
apoptosis in aortic endothelial cells. J Appl Toxicol 2013;33:364-9.

99. Saha D. Onion: Anti-cancer sulfur compounds with high cancer chemo prevention potentials. Sci Technol Arts Res J 2013;2:1-2.

100. Xiao H, Parkin KL. Isolation and identification of potential cancer chemopreventive agents from methanolic extracts of green onion (Allium cepa). Phytochemistry 2007;68:1059-67.

101. Kucuk O. Cancer chemoprevention. Cancer Metastasis Rev 2002;21:189-97.

102. Ma ZF, Ahmad J, Zhang H, Khan I, Muhammad S. Evaluation of phytochemical and medicinal properties of Moringa (Moringa oleifera) as a potential functional food. S Afr J Bot 2020;129:40-6.

103. Goyal A, Sharma V, Upadhyay N, Gill S, Sihag M. Flax and flaxseed oil: An ancient medicine and modern functional food. J Food Sci Technol 2014;51:1633-53.

104. Lattanzio V, Kroon PA, Linsalata V, Cardinali A. Globe artichoke: A functional food and source of nutraceutical ingredients. J Funct Foods 2009; 1:131-44.

105. Gul K, Yousuf B, Singh AK, Singh P, Wani AA. Rice bran: Nutritional values and its emerging potential for development of functional food a review. Bioact Carbohydr Diet Fibre 2015;6:24-30.
106. DeLuca JA, Garcia-Villatoro EL, Allred CD. Flaxseed bioactive compounds and colorectal cancer prevention. Curr Oncol Rep 2018;20:59

107. Anjum S, Sundaram S, Rai GK. Nutraceutical application and value addition of banana (Musa paradisica L. Variety "Bhusawal Keli") Peel: A review. Int J Pharm Pharm Sci 2014;6:81-85.

108. Galasso C, Gentile A, Orefice I, Ianora A, Bruno A, Noonan DM, et al. Microalgal derivatives as potential nutraceutical and food supplements for human health: A focus on cancer prevention and interception. Nutrients 2019;11:1226.

109. Jew S, AbuMweis SS, Jones PJ. Evolution of the human diet: Linking our ancestral diet to modern functional foods as a means of chronic disease prevention. J Med Food 2009;12:925-34.

110. Asgary S, Rastqar A, Keshvari M. Functional food and cardiovascular disease prevention and treatment: A review. J Am Coll Nutr 2018;37:429-55.

111. Zeng YW, Yang JZ, Pu XY, Du J, Yang T, Yang SM, et al. Strategies of functional food for cancer prevention in human beings. Asian Pac J Cancer Prev 2013;14:1585-92. 